\title{
Diffusion and Adoption of Smart Media in China
}

\author{
Sang-Hyun Hwang ${ }^{1}$, Joon-Ho Lee ${ }^{2}$, Ying $\mathrm{Hu}^{3}$ \\ ${ }^{1}$ Assistant Professor, Department of Advertising \& PR, Dong-eui University, Korea, moca@deu.ac.kr \\ ${ }^{2}$ Professor, Department of Communication \& Media, Dong-eui University, Korea, joonlee@deu.ac.kr \\ ${ }^{3}$ Professor, School of Journalism and Communication, China West Normal University, China, \\ huying0906@gmail.com
}

Corresponding Author: Joon-Ho Lee

\begin{abstract}
The purpose of this study is to analyze how theoretically suggested adoption factors have influenced the adoption of smart media (or devices) among Chinese users. More specifically, the study empirically explores relationships between new technology adoption factors: (individual characteristics, perceived attributes of smart devices, mass media usage) and smart media adoption. An online survey using Sojump, a Chinese online research platform, was conducted on a sample of 428 respondents of whom 139(32.5\%) were male and 289(67.5\%) were female. After a series of regression analyses, the following results were found. First, demographic characteristics and especially the characteristic of income, were significant predictors of subsequent media adoption. Second, whether the subject had an adventurous personality, their attitude toward social change, and the type of communication channels they used were all influential factors that shaped subsequent media adoption. Third, the perceived relative advantage and complexity of media platform affected both the adoption level and the intention of the subjects. Fourth, as the amount of television viewed by each subject increased so too did the adoption level and adoption intention. In conclusion, these results partially support previous theoretical assumptions but more importantly, they provide media practitioners, smart media producers, and marketers with extended, advanced, and meaningful insights and ideas that will help in understanding Chinese smart media users and to increase the future adoption level.
\end{abstract}

Keywords: Smart Media, Smart Device, Diffusion, Adoption, New Technology

\section{Introduction}

The worldwide introduction and rapid adoption of smart devices, including smartphones, tablet personal computers (PCs), smart televisions (TVs), wearables, and smart homes since 2010, have radically impacted the adoption and use of digital media. As of 2020 , over $50 \%$ of people in technologically advanced countries have adopted three or more types of smart devices which work based on high-speed Internet and which use mobile networks[1]. This revolutionary transformation of media and devices is changing communication modes and the daily routines of people as well as nearly every aspect of an individual's social and economic life.

Statistics and reports throughout the world clearly show that the global penetration of smart media devices has been consistently approaching a saturated level. There are several ways this saturation is evident: First, the number of global smartphone users has reached almost six billion as of 2020 which is a growth rate of ten times over the past ten years. Second, the proportion of smart TV (or connected TV)

Received: July 17, 2021; $1^{\text {st }}$ Review Result: September 03, 2021; $2^{\text {nd }}$ Review Result: October 19, 2021 Accepted: November 30, 2021 
began to exceed $60 \%$ of the total TV device in 2018[2]. Third, the number of global sales of table PCs, that have been gradually substituting PCs together with laptop computers, has increased ten times during the last ten years with the number reaching 500 million in 2020[3]. Finally, wearable devices such as watches, glasses, accessories, shirts, and shoes, are now additional innovative devices and are being given wide and careful attention as important tools in the Internet of Things (IoT) that improve virtual connections among humans, between humans and non-human objects, and among non-human objects. Smartwatches are the most popular type of wearable device and more than 200 million of them were sold in the past year. The total market size of wearable devices is about the same as that of tablet PC in 2020[4].

The technological development and widespread use of smart devices largely depend on individual consumer considerations, choices, and adoption behaviors. In order to explore the phenomenon regarding the rapid adoption of smart devices, it is necessary not only to examine the present situation in which how widely the devices are sold and used but also to analyze relationships between traits of consumers and their actual adoption of the new media and devices. For this reason, several theoretical explanations have been suggested since the 1960s. Across a variety of academic fields, diverse theoretical assumptions and hypotheses have been suggested or tested to explore relationships between the factors influencing adoption of innovative technologies and the actual adoption of them. The first and the most representative of these theoretical frameworks was the diffusion of innovations theory Rogers originally developed to make suggestions and testify in the 1960s[5].

As the next step in this process, it is now vital to empirically explore how different characteristics and perceptions of people cause the decision and adoption to use new smart media or devices in China. Therefore, this study analyzed social-psychological characteristics of new media users, their perceptions of new media or devices and their subsequent media usage patterns, as well as the effects of these characteristics on the level of actual adoption and the user's intention of further adoption. In order to do this, a randomized online survey was conducted to gather empirical data from Chinese smart media users, and the data were analyzed using multiple regression techniques.

\section{Literature Review}

\subsection{The Present Adoption and Use of Smart Devices in China}

As of 2021, the Chinese population is the world's largest and its total economic size and power are second only to the United States. The country still has a relatively high annual economic growth rate of over 6\% except for the minus economic growth rate in 2020 resulting from the COVID-19 epidemic. Chinese Gross Domestic Product (GDP) is expected to become higher than that of the USA by 2030[6]. This means that Chinese media users have steadily increasing purchasing power for a variety of up-todate media and devices, and that the consumers will likely adopt more and newer forms of emerging electronic gadgets in the future.

More than one billion Chinese people adopted and are using smartphones, and annual smartphone sales in China in the last five years exceeded 400 million devices. Also, the number of tablet PCs sold in China has been over 20 million per year since the early 2010s. This rapid growth and high degree of mobile smart device penetration in China mainly came from the development of mobile Internet facilities and high usage rate of mobile Internet nationally. Ninety-nine percent of Internet users in China also use mobile Internet. China's mobile payment (fin-tech) industry is growing. In 2020, the total transaction value of mobile payments, instead of paying in cash or with plastic cards has increased to 432 trillion yuan. This is up almost $21 \%$ as compared to the previous year. That year, there were more than 123 billion mobile payment transactions throughout the country[7].

As of 2020, household penetration of smart TVs in China has exceeded $50 \%$, with more than $60 \%$ of 
TV viewers watching TV by using smart TVs connected to the Internet with diverse applications and links to web platforms and services[7]. TV still maintains its functional position in the center of active home entertainment systems with a big high-quality screen and an audio system. However, TV viewing behaviors are becoming more active and purposive with the help of synchronous connections to the Internet and other digital devices[8]. Smart TV's functionally superior characteristics and innovativeness compared to traditional TV have naturally attracted media users' attention. This is because they function well as a complement to small mobile devices for viewing an abundance of movies, IPTV, and on-line video services such as over-the-top (OTT) in China. The size and content of these video industries in China are the biggest in the world.

Most other types of smart media and devices, such as wearable devices and realistic media, are of special interest in technologically advanced countries and those countries where smartphones and tablet PCs have reached their saturation point in the adoption process. The production and sales of these types of smart media have also been led by China to a large extent. In the case of the wearable device market, popular forms include wristwatches, glasses, accessories, clothes, and shoes, and their preferred functions are now for physical and mental health, security, navigation, fitness, IoT, entertainment, and environmental monitoring[8]. The wearable technology market made its way to China ten years ago, and this sector has seen triple-digit growth with little indication of any change in this pattern in the foreseeable future. China's wearables market started to overtake the US in 2017. More than a fifth (21\%) of adult internet users in China were donning a wearable device, such as an Apple Watch or Mi Band, at least once per month by 2017. By comparison, wearables penetration in the US had only reached $20.4 \%$ in the same period[9].

Therefore, it is necessary to understand contemporary smart media adoption behavior among Chinese consumers by analyzing how they adopt and use smart devices. Also, it is important to analyze underlying social-psychological factors influencing their adoption behavior.

\subsection{Diffusion of Innovations Theory}

According to the diffusion of innovations theory, originally proposed by Rogers, innovative ideas, new ways of solving problems, new technologies, and new media or devices are diffused and adopted in society in predictable patterns, especially in an S-shaped curve[5]. This theory provided a representative empirical and theoretical foundation that explained how new media and information technologies and new concepts or ideas are accepted and actually used on a societal scale. According to this theory, the speed of diffusion of innovation, the intention to adopt them and the adoption process are affected by (1) individual differences such as demographics, social-psychological characteristics, (2) the perception of and attitude toward the new innovative technologies, (3) the adoption of other new technologies, (4) the use of preexisting technologies, (5) the social circumstances, and (6) the communication channels for information-seeking and decision-making.

Rogers proposed five different types of adopters according to their time and intention to adopt new ideas and products. The adopters in a society are categorized and distributed in a bell-shaped, quasinormal distribution curve; These five types of adopters are: (1) Innovators who are venturesome and cosmopolites who occupy $2.5 \%$ of the entire population, (2) Early adopters who are respected or serve as a role model that make up $13.5 \%$ of the population, (3) The early majority who are deliberate and account for $34 \%$, (4) The late majority who are skeptical and are 34\%, (5) The laggards and resisters who like to stay traditional and make up the final $16 \%$. Many diffusion researchers who have observed the innovation-decision process of their respondents concluded that there was a common set of innovation-decision stages; (1) knowledge, (2) persuasion, (3) decision, (4) implementation, and (5) confirmation. It is also apparent from the research trend that mass communication and media are both decisive factors in the knowledge stage while interpersonal familiarity, peer communication, and an 
adopter's individual characteristics are important factors influencing from the second through to the final stages[10].

He also proposed two dimensions of contributing factors that influence the adoption of innovations following his research about how new hybrid corn seeds were adopted and used by farmers in the 1960s. One of these dimensions is the perceived attributes of innovations, and the other is the characteristics of adopter categories including socio-economic status, personality values, and communication behavior[11].

To be more specific, first, the perceived attributes of innovations are as follows.

(1) Relative advantage

"the degree to which an innovation is perceived as being better than the idea it substitutes"

(2) Compatibility

"the degree to which an innovation is perceived as consistent with the existing values, past experiences, and needs of potential adopters"

(3) Complexity

"the degree to which an innovation is perceived as relatively difficult to understand and use"

(4) Trialability

"the degree to which an innovation may be experimented with on a limited basis"

(5) Observability

"the degree to which the results of an innovation are visible to others"

Second, an adopter's individual characteristics consist of the following three factors.

(1) Social-economic status

Earlier adopters are generally younger or middle-aged, have a higher education, higher income, higher social class, or greater upward social mobility than do later adopters.

(2) Personality variables

In comparison to later adopters, earlier adopters have; greater empathy, less dogmatism, a greater ability in dealing with abstractions, greater rationality, more intelligence, a more favorable attitude toward change and toward science, a better ability to cope with uncertainty and risk, less fatalism, and/ or higher aspiration.

(3) Communication behavior

Earlier adopters are more cosmopolitan than are later adopters. They seek information about innovations, and have more social participation, more contact with change agents, greater exposure to mass and interpersonal communication channels, greater knowledge of innovations, and/ or a higher degree of opinion leadership than do later adopters.

\subsection{Prior Research Findings}

\subsubsection{Diffusion and Adoption of Smartphones, Tablet PCs, and Smart TVs}

In a replication study about the diffusion of smartphone users and their adoption and use, demographical characteristics proved important to predicting subsequent adoption behavior. Also, certain social-psychological variables such as 'innovativeness' and 'inspiration' (motivation to success) were related to the decision whether to adopt a smartphone. Some perceived attributes of smartphones including relative superiority, complexity, and trialability - affected the adoption decision and the intention to adopt them. Adoption or subscription to other new media was positively related to adoption behaviors and attitudes. The amount of use of such conventional media as TV viewing, newspaper reading, movie watching at theaters, internet usage, the amount of radio listening, and video watching partially affected smartphone adoption behaviors. In addition, difference between the two main channels of adoption - interpersonal channel and mass media channel - was not a significant factor explaining the 
adoption attitude and behavior[12].

Another study of the factors influencing the adoption of smart TVs tried to apply all the possible independent variables suggested by the theory of diffusion of innovations. Age and income were significant factors when deciding whether or not to purchase a smart TV with the younger and higher in income being the more likely to adopt. Among the perceived attributes of smart TV, 'relative advantage', 'observability', and 'trialability' were found to be positively related to adoption behavior and attitude respectively. Personality factors such as 'satisfaction with conventional TV', 'inspiration', 'attitude toward social change', and 'dogmatism' were significant predictors for smart TV adoption. Some variables regarding the use of other media (other new media use, TV viewing, and movie theater going) were also found to be positively related to smart TV adoption and usage intention[13]. There was an additional study about the adoption of Smart TVs that focused on perceived functional attributes of smart TVs. The study concluded and emphasized that 'relative advantage' was the attribute that had the greatest influence on the purchase intention and the subsequent use of smart TV followed by the level of compatibility, the perceived entertainment value, the usage of the Internet and availability of n-screen functions[14].

In one comprehensive study about ablet PC diffusion, it was found that some other factors for adoption were apparent. A macro-level study examined factors influencing tablet PC diffusion in 43 countries. The results showed that a lower tablet PC price contributed to wider tablet PC diffusion, and that higher levels of social network penetration and income increased the initial diffusion of tablet PCs. The study also found that tablet PCs were a complement to smartphones in the early diffusion period of a smart device, and that tablet PCs and smartphones are likely to substitute for traditional PCs in the initial diffusion period of tablet PCs[15].

\subsubsection{Diffusion and Adoption of Augmented Reality Devices}

Recent market studies demonstrated that augmented reality (AR) devices, such as smart glasses, will substantially influence the media industry. One study, in particular, investigated the role of personality in predicting the awareness and adoption of smart glasses - Google Glass or the Microsoft HoloLens. The results showed that open-minded and emotionally stable consumers tend to be more aware of Google Glass. According to this study, consumers who perceive the potential for high functional benefits and the social conformity of smart glasses afford the user are those more likely to adopt such wearables. A Consumer's individual personality, especially their level of openness to experience and their level of extraversion and neuroticism were important variables to consider[16]. Another similar study examined more factors that were thought to be associated with the adoption of smart wearable devices. The study explored the contributing and inhibiting factors that influence the adoption of wearable devices (Google Glass and Sony Smart Watch 3) through in-depth interviews with two groups (students and workers). In terms of smart glasses, trialability (look-and-feel) was the most influential factor, whereas, for smartwatches relative advantage (the function of fitness) was the key factor for adoption. In addition, factors which were linked to image, design, and a user's personal values (i.e., their needs and interest), were especially important for both the student and working groups[17].

\subsection{Theoretical Framework for Analysis}

As mentioned above, the smart media adoption rate has been increasing at a fairly quick pace throughout the world. Smartphones have been adopted by nearly everyone in technologically advanced countries, however most other types of smart devices that emerged in the market later were still under their diffusing process with an adoption rate of under 50\%. In China, there are many more possibilities and there is room for additional massive acceptance of devices compared to most other countries. It is helpful to explore what has made Chinese users adopt smart devices and what will make the users adopt 
new or additional devices. For the purpose of this research, it is necessary to analyze the causal relationship between factors influencing the adoption of smart media. When summarizing literature and prior research findings, three main categories of adoption factors were proposed and organized as follows;

(1) Individual characteristics of users

(1-1) Demographic characteristics: sex, age, income, education

(1-2) Personality factors: adventurousness, aspiration, cosmopolitism, sympathy, dogmatism, rationality, attitude toward social change

(1-3) Communication channels for adoption: channels for cognition and decision of innovation

(2) Perception of technological attributes of smart devices

: relative advantage, compatibility, complexity, trialability, observability

(3) Amount of daily mass media usage: TV, Internet, radio, newspaper, OTT, movie theater

These would have influenced in turn a series of two-layer adoption effects, as follows;

(1) Adoption level, meaning the number of smart devices already adopted

(2) Adoption intention, meaning being ready to adopt additional or new smart devices

The following theoretical model was proposed based on the findings of prior studies shown above [Fig. 1].

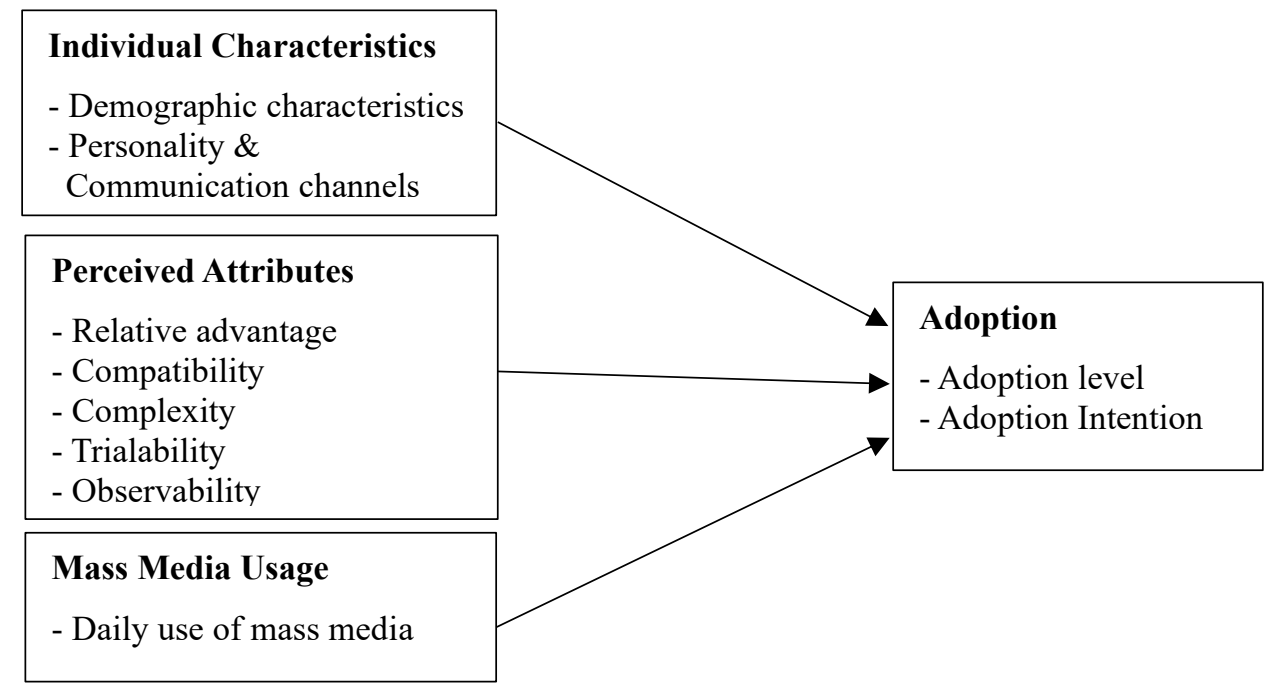

[Fig. 1] Smart Device Adoption Model for Analysis

\subsection{Research Questions}

Based on the purpose of the study and the newly designed theoretical framework, the following research questions are proposed:

RQ 1. What is the relationship between Chinese user characteristics and the adoption level and intention of smart devices?

RQ 2. What is the relationship between the user's perceived attributes of smart devices and the adoption level and intention of smart devices?

RQ 3. What is the relationship between the user's mass media use and the adoption level and intention of smart devices? 


\section{Method}

\subsection{Research Design}

This study used a randomized Internet survey to gather sufficient and useful data on the variables proposed in the research framework (Fig. 1) from anonymous Chinese smart media users. Before conducting the Internet survey, a questionnaire was made based on the theoretical assumptions suggested by Rogers and on useful operationalized questions used in prior relevant studies.

\subsection{Research Respondents}

The total number of answers was 798, however the final sample size selected for analysis was 428 . Only adult respondents over the age of 20 were selected because the purchasing ability for smart devices had to be considered. Also, there were many respondents who skipped an unacceptable number of essential questions. Due to the known limitations of this kind of web survey, a proportionate distribution of traits in the sample (sex, age, income, education) was not fully accomplished (Table 1).

[Table 1] Demographical Characteristics of Respondents ( $\mathrm{N}=428)$

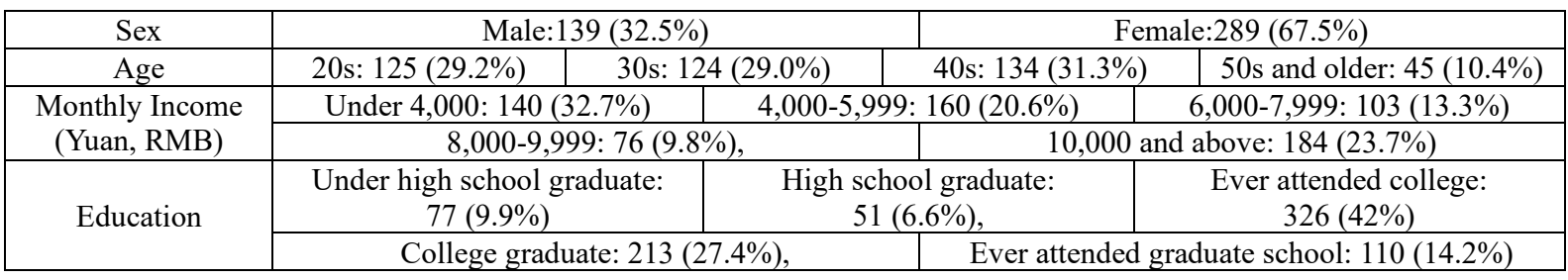

\subsection{Instrument}

The first draft of the questionnaire was carefully reviewed and edited by the authors and two professors who are specialized in the field of social studies and new communication media. Then, a pilot survey was conducted using 15 Chinese smart media users to check if there were satisfactory degrees of reliability and validity among the questions. The questionnaire consisted of the following six parts and most of them were measured using Likert Scales;

(1) The types and the number of smart media, devices, or services that were adopted and used - smartphones, smart TVs, tablet PCs, wearables, smart home devices (scored from 0 to 5)

(2) The Intention to purchase or accept additional or new devices or services - smartphones, smart TVs, tablet PCs, wearables, smart home devices (scored from 0 to 5)

(3) Daily usage of mass media - TV, Internet, radio, newspaper, OTT, movie theaters (5-point scales)

(4) Personality and Communication factors - adventurousness, aspiration, cosmopolitism, sympathy, dogmatism, rationality, attitudes toward social change, diversity of communication channels (5scales)

(5) Perceived attributes of smart media that were adopted or not adopted - relative advantage, compatibility, complexity, trialability, observability (5-point scales)

(6) Demographics - sex (2-point dummy scale), age, income, education (5-point scale)

\subsection{Data Collection}

The questionnaire was first uploaded on a website managed by Sojump (问卷星, www.sojump.com) which is a Chinese service provider engaged in the development of online questionnaires, examinations and voting platforms. Second, the URL link of the survey was randomly distributed on the WeChat 
messenger platform to attract and induce randomly accessed people to the survey. A repeat when answering questions by a respondent was prohibited. The survey was performed for a month; from midNovember to mid-December, 2020.

\subsection{Analysis}

To gain solutions to these three research questions, a series of multiple regression analyses were conducted to explore linear causal relations between a factor set of three types which were independent variables and an adoption variable set of two types which were dependent variables.

\section{Results}

\subsection{The RQ 1. Relationship between User Traits and Adoption}

As shown in [Table 2], the individual traits of users were recategorized into two types - traits with demographical characteristics and traits involving the personality/communication channel. The demographical traits, including sex, age, income, and education, explained and predicted $6.2 \%$ of the total variance of smart device adoption level, and $8.0 \%$ of that of the adoption intention (Adjusted $\mathrm{R}^{2}=.062$ and .080 , respectively). Also, the variables of the personality and communication channel explained and predicted $3.2 \%$ of the total variance of smart device adoption levels, and $4.1 \%$ of that of the adoption intention (Adj. $\mathrm{R}^{2}=.032$ and .041 , respectively). All the demographical variables of sex, age, income, and education proved statistically significant in affecting the adoption level of smart devices. Those who were female, higher in age, income, or education had already adopted more kinds of smart devices than those who were male or lower counterparts. In terms of intention to adopt additional devices, only income was positively related. The higher the income level, the stronger the adoption intention $(\beta=.214 ; \mathrm{t}=3.828, \mathrm{p}<.001)$. Those users who were more adventurous, had a positive attitude toward social change, or used more diverse communication channels, and were more likely to adopt more kinds of smart media $(\beta=.299, \mathrm{p}<.05 ; \beta=.236, \mathrm{p}<.01 ; \beta=.185, \mathrm{p}<.05)$. These three variables plus a higher rationality significantly contributed to the stronger intention to adopt additional or new media $(\beta=.169, p<.05 ; \beta=.179, p<.05 ; \beta=.221, p<.05 ; \beta=.182, p<.05)$.

[Table 2] Multiple Regression between Individual Factors and Adoption ( $\mathrm{N}=428)$

\begin{tabular}{|c|c|c|c|c|c|c|c|c|c|}
\hline \multirow{2}{*}{\multicolumn{2}{|c|}{ Factors }} & \multicolumn{4}{|c|}{ Adoption Level } & \multicolumn{4}{|c|}{ Adoption Intention } \\
\hline & & $\beta$ & $\mathrm{t}$ & $\mathrm{p}$ & Adj. R2 & $\beta$ & $\mathrm{t}$ & $\mathrm{p}$ & Adj. R2 \\
\hline \multirow{4}{*}{ Demographics } & Sex & .258 & 2.029 & $.043 *$ & \multirow{4}{*}{.062} & -.307 & -11.182 & .113 & \multirow{4}{*}{.080} \\
\hline & Age & .187 & 2.852 & $.005^{* *}$ & & .059 & .635 & .526 & \\
\hline & Income & .106 & 2.649 & $.008 * *$ & & .214 & 3.838 & $.000^{* * *}$ & \\
\hline & Education & .142 & 2.957 & $.003 * *$ & & -.049 & -.705 & .482 & \\
\hline \multirow{8}{*}{$\begin{array}{l}\text { Personality \& } \\
\text { Communication }\end{array}$} & Adventurousness & .169 & 2.045 & $.029 *$ & \multirow{8}{*}{.032} & .169 & 1.998 & $.041 *$ & \multirow{8}{*}{.041} \\
\hline & Aspiration & .052 & .896 & .371 & & .066 & .079 & .405 & \\
\hline & Cosmopolitism & .043 & .678 & .498 & & .049 & .630 & .529 & \\
\hline & Sympathy & .034 & .494 & .621 & & .026 & .312 & .755 & \\
\hline & Dogmatism & .021 & .396 & .693 & & .106 & 1.652 & .099 & \\
\hline & Rationality & .029 & .513 & .608 & & .182 & 2.077 & $.031 *$ & \\
\hline & $\begin{array}{l}\text { Attitude toward } \\
\text { social change }\end{array}$ & .236 & 3.131 & $.002 * *$ & & .179 & 2.068 & $.033^{*}$ & \\
\hline & $\begin{array}{l}\text { Communication } \\
\text { channel diversity }\end{array}$ & .185 & 2.072 & $.030^{*}$ & & .221 & 2.147 & $.025^{*}$ & \\
\hline
\end{tabular}




\subsection{RQ 2. Relationship between Perceived Attributes of Smart Media and Adoption}

[Table 3] presents causal linear relationships between perceived attributes of smart media and the subsequent adoption level and intention. In terms of the explaining and predicting power of the five independent variables on each of the two dependent variables, 3.3\% and $4.7 \%$ were measured (Adj. $\mathrm{R} 2=.033$ and .047 , respectively). There was only one variable that affected the adoption level. The complexity in using smart media was negatively related to the adoption level, meaning that those users who perceived that the smart devices were easy to use tended to adopt more kinds of devices $(\beta=-.095$, $\mathrm{p}<.05)$. The adoption intention was significantly influenced by its relative advantage, complexity and trialability. Those who thought that newer smart media were functionally better, easier to use, and more triable to use had a stronger intention to adopt or purchase them in the near future $(\beta=.126, p<.05 ; \beta=$ $-.138, \mathrm{p}<.05 ; \beta=.125, \mathrm{p}<.05)$.

[Table 3] Multiple Regression between Perceive Attributes of Devices and Adoption ( $\mathrm{N}=428)$

\begin{tabular}{|c|c|c|c|c|c|c|c|c|}
\hline \multirow{2}{*}{$\begin{array}{l}\text { Adoption } \\
\text { Perceived attributes }\end{array}$} & \multicolumn{4}{|c|}{ Adoption Level } & \multicolumn{4}{|c|}{ Adoption Intention } \\
\hline & $\beta$ & $\mathrm{t}$ & $\mathrm{p}$ & Adj. R2 & $\beta$ & $\mathrm{t}$ & $\mathrm{p}$ & Adj. R2 \\
\hline Relative advantage & .050 & .903 & .367 & \multirow{5}{*}{.033} & .126 & 1.987 & $.039 *$ & \multirow{5}{*}{.047} \\
\hline Compatibility & -.005 & -.100 & .920 & & .028 & .478 & .478 & \\
\hline Complexity & -.095 & -2.023 & $.043^{*}$ & & -.138 & -2.560 & $.011^{*}$ & \\
\hline Trialability & -.028 & -.570 & .569 & & .125 & 1.970 & $.047 *$ & \\
\hline Observability & -.055 & -1.194 & .233 & & .078 & 1.335 & .182 & \\
\hline
\end{tabular}

\subsection{RQ 3. Relationship between Mass Media Use and Smart Media Adoption}

In [Table 4], the independent variable set which consisted of the amount of daily use of 5 mass media explained $4.3 \%$ of total variance for the adoption level and $9.2 \%$ of the variance of the adoption intention (Adj. R2 $=.043$ and .092 , respectively). Among the media use amount variables, TV viewing time was positively decisive in predicting both adoption variables $(\beta=.098, \mathrm{p}<.05 ; \beta=.257, \mathrm{p}<.001)$. More TV viewing time seemed to lead users to adopting more smart devices and to intending to adopt more of them. The amount of movie watching in theaters was also a significant factor influencing the adoption level $(\beta=.104, \mathrm{p}<.01)$, and newspaper reading was an additional influential factor for the adoption intention $(\beta=.111, \mathrm{p}<.01)$.

[Table 4] Multiple Regression between Mass Media Use and Adoption ( $\mathrm{N}=428$ )

\begin{tabular}{|c|c|c|c|c|c|c|c|c|}
\hline \multirow{2}{*}{ Media Use Adoption } & \multicolumn{4}{|c|}{ Adoption Level } & \multicolumn{4}{|c|}{ Adoption Intention } \\
\hline & $\beta$ & $\mathrm{t}$ & $\mathrm{p}$ & Adj. $R^{2}$ & $\beta$ & $\mathrm{t}$ & $\mathrm{p}$ & Adj. $R^{2}$ \\
\hline TV & .098 & 2.276 & $.023 *$ & \multirow{6}{*}{.043} & .257 & 5.601 & $.000 * * *$ & \multirow{6}{*}{.092} \\
\hline Internet & .050 & 1.112 & .266 & & .003 & .071 & .944 & \\
\hline Radio & -.039 & -.630 & .529 & & .023 & .381 & .704 & \\
\hline Newspaper & .027 & .584 & .559 & & .111 & 2.220 & $.008 * *$ & \\
\hline OTT & -.058 & -1.337 & .182 & & .002 & .047 & .983 & \\
\hline Movie Theater & .104 & 2.783 & $.006^{* *}$ & & .018 & .395 & .693 & \\
\hline
\end{tabular}




\section{Discussion}

This study analyzed the causal relationships between theoretically proposed adoption factors and the subsequent adoption level and intention among smart media users in China. In this environment, rapid technological breakthroughs of smart media and devices have made more and more users and consumers pay attention to and depend on smart media in daily life. During this analysis of the influence of the personal factors on smart media adoption, the following findings were generated and need to be practically emphasized.

(1) All the demographical characteristics are significant criteria for discerning adopters and nonadopters and the adoption level of smart media. Among them, income is the only significant predictor of further adoption of the new media.

(2) Those who are more adventurous, more favorable to rapid social change, or more open to diverse types of communication channels, tend to have adopt early and tend to adopt more smart devices.

(3) Users who perceive that new media or devices are not easy to use do not tend to adopt the devices. However, the users intend to adopt more when new media are perceived to be relatively advanced and easily testable.

(4) The amount of TV viewing is closely related to both the adoption level and intention to adopt. In addition, the frequency of movie theater-going is positively related to the adoption level, whereas the amount of newspaper reading is positively related to the adoption intent. This implies that more active pursuers of content among mass media also tend to be more interested in smart media usage.

\section{Conclusion}

The findings of this study partially support hypothetical propositions of the theory of diffusion of innovations and are consistent with some of prior research findings. They will provide media practitioners and smart media producers and marketers in the Chinese market with some extended, advanced, and meaningful ideas and insights as follows;

(1) To increase the future smart device adoption level, device prices, complexity, and uncertainties, which are frequently accompanied by decision-making processes of adoption, need to be reduced.

(2) The number of opportunities to demonstrate distinct functions of devices and to enable consumers to see and use new media needs to be increased.

(3) The utilization of opinion leaders in viral marketing and TV programs along with TV advertising about smart media can help contribute to more active adoption intention and behavior.

This study suffered two limitations. The first is that there was a relatively larger proportion of female respondents $(67.5 \%)$ in the sample. The second was that the independent variable groups mainly included classic variables proposed by the early theoretical assumptions and studies. This resulted in the relatively low R-squared values accounted for by the selected independent variables on a series of multiple regression analyses in this study. It is suggested that future studies acquire more proportionate survey data and search and develop more variables that are appropriate for up-to-date media and technology adoptions. In addition, it could be more valuable and comprehensive to compare the findings of this study to those of other studies conducted in other countries.

\section{Acknowledgments}

This work was supported by Dong-eui University Foundation Grant (202101610001). 


\section{References}

[1] https://www.pinterest.co.kr/pin/245375879681485288/, Jun 30 (2021)

[2] http://www.newstomato.com/readNews.aspx?no=841289/, Jul 6 (2021)

[3] http://cnkglobal.co.kr/bbs/board.php?bo_table=news\&wr_id=298/, Jul 3 (2021)

[4] http://www.epnc.co.kr/news/articleView.html?idxno=98607/, Jul 3 (2021)

[5] E. M. Rogers, Communication Technologies: The New Media in Society, Free Press, (1986)

[6] https://www.worldbank.org/en/news/video/2021/06/29/china-economic-update-june-20/, Jun 29 (2021)

[7] https://news.kotra.or.kr/user/globalBbs/kotranews/782/globalBbsDataView.do?setIdx=243\&dataIdx=174485/, Jul 4 (2021)

[8] https://m.blog.naver.com/PostView.naver?isHttpsRedirect=true\&blogId=mtmag\&logNo=220040429840/, Jun 28 (2021)

[9] https://www.marketing-interactive.com/chinas-wearables-market-to-surpass-us-this-year/, Jun 28 (2021)

[10] E. M. Rogers, Diffusion of Innovations, 4th ed., Free Press, (1995)

[11] E. M. Rogers, Diffusion of Innovations, 5th ed., Free Press, (2003)

[12] S. H. Kim, An Analysis of Smartphone Adoption Factors and Behaviors Based on Functional Characteristics, Diffusion Theory, and Technology Acceptance Model, Dong-eui University, Doctoral Dissertation, (2011)

[13] J. H. Lee, Factors Adopting Smart(Connected) Television: A Comparative Analysis of the Models of Diffusion of Innovations and Technology Acceptance, Locality and Communication, (2015), Vol.19, No.3, pp.125-167, UCI : G704SER000001556.2015.19.3.002

[14] Y. Bae, H. Chang, Adoption of Smart TVs: A Bayesian Network Approach, Industrial Management \& Data Systems, (2012), Vol.112, No.6, pp.891-910, DOI: https://doi.org/10.1108/02635571211238509

[15] S. Lee, S. Lee, S. Chan-Olmsted, An Empirical Analysis of Tablet PC Diffusion, Telematics and Informatics, (2017), Vol.34, No.2, pp.518-527, DOI: https://doi.org/10.1016/j.tele.2016.09.007

[16] P. A. Rauschnabel, A Brem, B. S. Ivens, Who Will Buy Smart Glasses? Empirical Results of Two Pre-Market-Entry Studies on the Role of Personality in Individual Awareness and Intended Adoption of Google Glass Wearables, Computers in Human Behavior, (2015), Vol.49, pp.635-647, DOI: https://doi.org/10.1016/j.chb.2015.03.003

[17] A. Adapa, F. F.-H. Nah, R. H. Hall, K. Siau, S. N. Smith, Factors Influencing the Adoption of Smart Wearable Devices, International Journal of Human-Computer Interaction, (2018), Vol.34, No.5, pp.399-409, DOI: https://doi. org/10.1080/10447318.2017.1357902 